FACULDADE DE CIÊNCIAS ECONÔMICAS DA UFRGS Análise
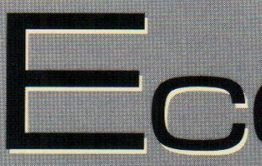

VALORES E PREÇOS DE PRODUÇÃO: UMA RELETURA de MARX Alfredo SAAD FILHO

OS ANTIGOS, OS NOVOS E OS NEO-INSTITUCIONALISTAS: HÁ CONVERGÉ NCIA TEÓ RICA NO PENSAMENTO INSTITUCIONALISTA

Octavio Augusto C. Conceição

A MENSURAÇÃ O DO GRAU DE INDEPENDÉNCIA DO BANCO CENTRAL: UMA ANÁLISE DE SUAS FRAGILIDADES HeLder Ferreira de MENDONÇA

A SUSTENTABILIDADE DA DÍVIDA MOBILIÁ RIA FEDERAL BRASILEIRA: UMA INVESTIGAÇĀ O ADICIONAL VIVIANE LUPORINI

O MODELO dE KRUGMAN EXPLICA A CRISE CAMBIAL. BRASILEIRA EM JANEIRO DE 1999?

Adriano CAMPOS MENEZES E TITO BELCHIOR S. MOREIR/

ESTRANGULAMENTO DA díVIDA EXTERNA E CRESCIMENTO ECONO MICO NA AMÉRICA LATINA: LIÇÓ ES DA DÉCADA DE 80

Marco Vaies buratto E SABino da SiLva P. JR.

CriaÇÃo e desvio de COMÉrCio: ANÁlise do FLuXo COMERCial ENTRE O Brasil. e O MERCOSUl para Alguns PRODUTOS INDUSTRIALIZADOS

Clá Udio Roberto fó fFano Vasconcelos

A EVOLUCÁ̃ DA INDÚ STRIA BRASILEIRA DE CELULOSE E SUA ATUAÇÃO NO MERCADO MUNDIAL

Emerson Martins HILGemberg e Carlos josé Caetano BACHA

A PROTEÇÃo SOCIAL NO PRIMEIRO QUARTEL DO SÉCULO XXI: BRINCANDO COM CENÁRIOS

rosa Maria Marques e Áquilas Mendes

ECONOMIA DO CRIME: ELEMENTOS TEÓ RICOS E EVIDÊNCIAS EMPÍRICAS

Gilberto José SChaefer e Pery Francisco Assis Shikida

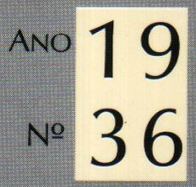


UNIVERSIDADE FEDERAL DO RIO GRANDE DO SUL

Reitora: Profa. Wrana Maria Panizzi

FACULDADE DE CIÊNCIAS ECONÔMICAS

Diretor: Prof. Pedro Cézar Dutra Fonseca

CENTRO DE ESTUDOS E PESQUISAS ECONÔMICAS

Diretor: Prof. Gentil Corazza

DEPARTAMENTO DE CIÊNCIAS ECONÔMICAS

Chefe: Prof. Luiz Alberto Oliveira Ribeiro de Miranda

DAPARTAMENTO DE CIÊNCIAS CONTÁBEIS E ATUARIAIS

Chefe: João Marcos Leão da Rocha

CURSO DE PÓS-GRADUAÇÃO EM ECONOMIA

Coordenador: Prof. Eduardo Pontual Ribeiro

CURSO DE PÓS-GRADUAÇÃO EM ECONOMIA RURAL

Coordenador: Prof. Jalcione Almeida

CONSELHO EDITORIAL: Achyles B. Costa, Aray M. Feldens, Carlos A. Crusius, Carlos G. A. Mielitz Netto, Eduardo A. Maldonado Filho, Eduardo P. Ribeiro, Eugênio Lagemann, Fernando Ferrari Filho, Gentil Corazza, Jan A. Kregel (Univ. of Bologna), Marcelo S. Portugal, Nali J. Souza, Otilia B. K. Carrion, Paulo A. Spohr, Paulo D. Waquil, Pedro C. D. Fonseca, Philip Arestis (Univ of East London), Roberto C. Moraes, Ronald Otto Hillbrecht, Stefano Florissi, Eleutério F. S. Prado (USP), Fernando H. Barbosa (FGV/RJ), Gustavo Franco (PUC/RJ), João R. Sanson (UFSC), Joaquim P. Andrade (UnB), Juan H. Moldau (USP), Paul Davidson (Univ. of Tennessee), Werner Baer (Univ. of Illinois).

COMISSÃO EDITORIAL: Eduardo Augusto Maldonado Filho, Fermando Ferrari Filho, Gentil Corazza, Marcelo Savino Portugal, Paulo Dabdab Waquil; Roberto Camps Moraes.

EDITOR: Fernando Ferrari Filho

EDITOR ADJUNTO: Pedro Silveira Bandeira

SECRETÁRIA: Vanessa Hoffmann de Quadros

REVISÃO DE TEXTOS: Vanete Ricacheski

FUNDADOR: Prof. Antônjo Carlos Santos Rosa

Os materiais publicados na revista Análise Econômica sāo da exclusiva responsabilidade dos autores. É permitida a reproduçāo total ou parcial dos trabalhos, desde que seja citada a fonte. Aceita-se permuta com revistas congêneres. Aceitam-se, também, livros para divulgação, elaboração de resenhas e recensões. Toda correspondência, material para publicação (vide normas na terceira capa), assinaturas e permutas devem ser dirigidos ao seguinte destinatário:

PROF. FERNANDO FERRARI FILHO

Revista Análise Econômica - Av. João Pessoa, 52 CEP 90040-000 PORTO ALEGRE - RS, BRASIL Telefones: (051) 316-3348 e 316-3440 - Fax: (051) 316-3990

E-mail: rae@vortex.ufrgs.br

Análise Econômica

Ano 18, n⿳3 33, março, 2000 - Porto Alegre

Faculdade de Ciências Econômicas, UFRGS, 2000

Periodicidade semestral, março e setembro.

1. Teoria Econômica - Desenvolvimento Regional -

Economia Agrícola - Pesquisa Teórica e Aplicada -

Periódicos. I. Brasil

Faculdade de Ciências Econômicas,

Universidade Federal do Rio Grande do Sul.

CDD 330.05

CDU 33 (81) (05) 


\title{
A evolução da indústria brasileira de celulose e sua atuação no mercado mundial
}

\author{
Emerson Martins Hilgemberg' e Carlos José Caetano Bacha ${ }^{2}$
}

\begin{abstract}
Resumo: Este texto analisa a evolução histórica da indústria brasileira de celulose, com especial atenção para o segmento exportador, mos trando que o desenvolvimento desta indústria foi, em grande parte, condicionado pelas políticas públicas que objetivaram, desde sempre, tornála competitiva no mercado mundial. Desta forma, a política pública, levada a cabo em boa parte pelo Banco Nacional de Desenvolvimento Econômico e Social (BNDES) contribuiu, de maneira decisiva, para a criação e organização do setor exportador de celulose brasileiro, tal qual ele se apresenta hoje. Os resultados desta política orientada para a criação de uma indústria capaz de gerar excedentes exportáveis são avaliados em seguida, considerando-se a evolução das exportações brasileiras de celulose. Além disso, são estabelecidas as principais características, tanto dos maiores concorrentes do Brasil, como também dos maiores mercados consumidores.
\end{abstract}

Palavras-chave: indústria brasileira de celulose; exportação de celulose; BNDES; mercado externo.

Abstract: This text analyzes the historical evolution of the Brazilian pulp industry, with special attention for its export segment. The work shows that the development of this industry was, largely, conditioned by the public politics that objectified, from its genesis, to turn it competitive in the world market. The stress point is that the public politics, carried out, mainly, by the National Bank of Economic and Social Development (BNDES) contributed, in a decisive way, for the creation and organization of the Brazilian pulp export segment, just as him comes today. Following this, the results of this politics are appraised. Finally, the main characteristics of the largest competitors of Brazil as well as of the largest consuming markets are established.

Key words: Brazilian pulp industry; pulp exports; foreign market.

\footnotetext{
: Professor do Departamento de Economia da UNICENTRO/PR e mestrando na ESALQ/USP.

${ }^{2}$ Professor Associado do Departamento de Economia, Administraçāo e Sociologia da ESALQ/ USP.
} 


\section{Introdução}

Este texto analisa a evolução histórica da indústria brasileira de celulose, em especial de seu segmento exportador, utilizando, basicamente, dados secundários analisados nas formas tabular e gráfica e dados primários obtidos de uma pesquisa de campo, realizada sob a forma de questionários enviados aos exportadores de celulose, a saber, Aracruz, Cenibra, Bahia Sul, Jari Celulose, Votorantim e Riocell ${ }^{3}$.

Para tanto, o trabalho divide-se em quatro seções. A seguinte (seção 2) tem o propósito de mostrar que o desenvolvimento desta indústria foi, em grande parte, condicionado pelas políticas públicas que objetivaram, desde sempre, torná-la competitiva no mercado mundial.

Os resultados da política pública orientada para a criação de uma indústria capaz de gerar excedentes exportáveis são avaliados na seqüência (seção 3), considerando-se a evolução das exportações brasileiras de celulose. Além disso, estabelecem-se as principais características, tanto dos maiores concorrentes do Brasil como também dos maiores mercados consumidores de sua celulose. Finalmente, a seção 4 apresenta as considerações finais.

\section{A evolução da indústria brasileira de celulose}

Conforme Scherer $\mathcal{Z}$ Ross (1990, p. 7), a política pública pode cumprir um papel estratégico na criação de vantagens competitivas para as empresas. Ela pode criar barreiras à entrada de determinados players no mercado ou facilitar a permanência de outros por intermédio de financiamentos de longo prazo, restrições para as importações ou planos de investimentos articulados com a iniciativa privada. Além disso, o governo pode influenciar no número de empresas existentes no mercado, estabelecendo condiçōes para que somente aquelas que obedeçam a certos requisitos sejam beneficiadas por determinadas políticas de incentivo.

No caso da indústria brasileira de celulose, é importante notar que o capital e o empresariado da indústria de papel têm suas raízes nas atividades de importação e comércio de papéis realizados por imigrantes. As

\footnotetext{
${ }^{3}$ Dos seis questionários enviados em março de 2000, quatro foram respondidos. Apesar dos vários contatos estabelecidos, a Bahia Sul e a Jari nāo responderam aos questionários. Não obstante, as empresas que retornaram os formulários representam, em conjunto, 79,48\% da capacidade instalada da induistria exportadora de celulose, de tal sorte que a análise nāo fica comprometida.
} 
principais empresas iniciaram suas atividades a partir da comercialização de papel importado, passando por atividades gráficas até evoluírem para a fabricação de papel. Note-se que, entre 1885 e 1925, são instaladas no país a Fábrica de Papel Paulista Salto, a Companhia Melhoramentos e a Companhia Fabricadora de Papel (que deu origem ao grupo Klabin), a fábrica de papelão Simão e Companhia (que originou o grupo Simão, adquirido, posteriormente, pela VCP), a Indústria de Papelão Limeira S.A. (que originou o grupo Ripasa), entre outros. Nesta época, a pasta de madeira e a celulose eram quase que totalmente importadas e a atividade florestal era completamente desvinculada da indústria do papel (Soto, 1992).

No final da década de 20, a indústria é atingida pela crise de 1929, a qual teve efeitos devastadores sobre os preços do café. Uma vez que parte significativa da economia brasileira dependia do desempenho deste produto, vários setores foram afetados, como a indústria de papel.

Diante da crise de superprodução de café (nosso principal gerador de divisas naquela época) e das grandes dificuldades financeiras atravessadas por muitas empresas, o governo proibiu - até 1937 - a importação de máquinas para a instalação de novas fábricas de papel e criou um fundo especial para soconrer as empresas em dificuldades. O resultado deste processo foi a concentração de capacidade de produção nas maiores empresas existentes.

Por outro lado, as dificuldades no balanço de pagamentos e a elevação do preço da celulose importada causada pela desvalorização da moeda nacional fizeram aparecer as condições para o sungimento de um segmento nacional produtor de pastas no país. Note-se que "em 1933 o Estado concedeu isenção de impostos de importação e taxas alfandegárias às máquinas, acessórios e todos os insumos necessários para as empresas organizadas com o fim de produzir celulose" (Suzigan citado por Soto, 1992).

Desta forma, as fábricas de papel obedeceram à lógica geral do modelo de substituição de importações, sendo criadas para atender a faixas de demanda que não podiam ser atendidas por importações - caso dos papéis de qualidade inferior, destinados a embrulhos e embalagens simples - e para fabricar papéis que, embora passíveis de importação, pressionavam de modo negativo o saldo da balança comercial, tais como os papéis de imprimir e escrever. Somente num segundo momento, quando a produção nacional de papéis passou a demandar uma quantidade de celulose que justificava a instalação de fábricas é que começaram a surgir as primeiras unidades, próximas aos locais onde havia a matéria-prima (BNDES, 1991).

Em 1934, o grupo Klabin adquiriu do Banco do Estado do Paraná a fazenda Monte Alegre e iniciou a implantação de uma fábrica de papel 
imprensa que também produzia pasta mecânica e celulose semibranqueada, dando origem ao processo de integração vertical na indústria. Inaugurada em 1946, ela era a maior fábrica de papel e celulose do país.

Para Mendonça Jorge (1992, p. 27), este empreendimento traça uma linha divisória no desenvolvimento da indústria de papel e celulose no país,

Em primeiro lugar, porque trata-se do primeiro projeto significativo de uma fábrica de papel integrada (produção conjunta de celulose e papel) e, sobretudo, utilizando recursos florestais nacionais. Em segundo lugar, porque é o primeiro projeto onde aparece uma relação explícita entre o Estado e a iniciativa privada, através de uma política pública deliberada de apoio ao desenvolvimento do setor.

No ano de 1950, o Brasil era praticamente auto-suficiente em produção de papel, exceto em papel imprensa. No entanto, importava mais de $70 \%$ da celulose de que necessitava.

Não obstante, no início da década de 50, começaram a surgir preocupações quanto à disponibilidade de matéria-prima para suprir a demanda mundial de celulose, pois as florestas de coníferas das regiões temperadas não seriam suficientes. Frente a isto, os países desenvolvidos voltaram-se com interesse para o aproveitamento de novas espécies florestais tropicais e temperadas, adaptando novas técnicas de produção e proporcionando ao Brasil a possibilidade de lançar-se como grande produtor de celulose (Paladino, 1985).

A produção brasileira de celulose de fibra curta passou de 1.590 toneladas em 1950 para 51.900 toneladas em 1956. Este aumento de produção baseou-se fundamentalmente no eucalipto. O govemo de São Paulo possuía reservas que foram plantadas desde o início do século para alimentar as caldeiras das locomotivas e fornecer dormentes para vias férreas. Quando, no pós-guerra, as locomotivas passaram a usar óleo diesel e tração elétrica tais reservas foram aproveitadas. Assim, a importação de celulose, que era de cerca de $73,7 \%$ do consumo aparente em 1950 reduziu-se a 28,8\% em 1960 (Soto, 1992 e Paladino, 1985).

Em 1955, a Cia. Suzano iniciou, em fase experimental, a produção de celulose de fibra curta de eucalipto e em 1961 foi produzido no Brasil, pela primeira vez no mundo, o primeiro papel feito integralmente com celulose de fibra curta.

O primeiro programa governamental de investimentos específicos para o setor de celulose e papel surgiu na segunda metade da década de 
50, inserido no Plano de Metas. Tal plano fixava, dentre outras coisas, a auto-suficiência do país na produção de celulose, mas, em 1959 as metas iniciais foram revistas para menos ${ }^{4}$.

Neste período, algumas empresas de capital estrangeiro entraram no setor, juntando-se à Rigesa, subsidiária da West Virginia, Pulp and Paper Company, fundada em 1953. Em 1958 foi constituída a Manville, subsidiária da Manville Corporation. Neste mesmo ano, também apareceu a Champion Papel e Celulose Ltda., subsidiária da Champion Papers Incorporation, que iniciou suas atividades em 1960, produzindo exclusivamente celulose de fibra curta. Esta última foi a primeira a exportar papel fabricado integralmente com essa celulose (Soto, 1992).

Até meados da década de 60 , o $\mathrm{BNDE}^{5}$ priorizava o setor de transportes, a expansão dos entrepostos de armazenagem e a geração de energia elétrica. Mesmo assim, em 1955 o Banco aprovou a concessão de financiamento à Celulose e Papel Fluminense S.A., seu primeiro passo em direção a um maior apoio ao setor. Entre 1955 e 1965, o financiamento ao setor era esporádico e ocasional (BNDES, 1991).

Em 1960, o país já produzia mais de $70 \%$ de seu consumo aparente de celulose, baseando-se fundamentalmente na produção de celulose de fibra curta. Nesse período, surgiram os primeiros excedentes exportáveis. No entanto, o país continuava deficitário na produção de celulose de fibra longa.

Em 1961, quatro empresas produziam exclusivamente celulose para o mercado: Champion, Cambará, Celulose Brasileira e Sacraft.

A partir da segunda metade da década de 60, o BNDE muda de atitude em relação ao setor de papel e celulose ${ }^{6}$.

\footnotetext{
${ }^{4}$ De acordo com Paladino (1985, p. 280, rodapé), as metas foram revistas devido a: (1) atraso nos projetos de produçāo de papel jornal; (2) montante excessivo de investimentos para a exploraçāo das reservas florestais; (3) pressão demasiada sobre o Balanço de Pagamentos e (4) conveniências de comércio exterior

${ }^{5} \mathrm{O}$ BNDE foi criado em 1952 e o "S" foi adicionado à sigla somente em 1982 quando o governo instituiu o Finsocial e repassou recursos desse fundo para o Banco, com a finalidade de financiar projetos sociais (BNDES, 1991)

${ }^{6}$ O Banco passou desde entāo a adotar uma postura de fomento, graças a três fatores fundamentais: (1) a tarefa original do Banco era a de reorganizar e aparelhar a infra-estrutura do país e isto foi feito de 1952 a 1964. Numa etapa posterior, o Banco passou a fomentar indústrias; (2) a partir de pesquisas realizadas no final da década de 50 , o Brasil conseguiu produzir, a partir do eucalipto, celulose de fibra curta de boa qualidade para a produçāo de papel de imprimir e escrever, proporcionando o surgimento de condiçōes para o país competir no mercado internacional; e, (3) a realização de um estudo, contratado pela Associação Nacional dos Fabricantes de Papel e Celulose (ANFPC) e financiado.pelo BNDE, que analisou profundamente as empresas do setor de papel e celulose no Brasil, fornecendo aos analistas do Banco informações confiáveis sobre o setor (BNDES, 1991).
} 
Nesta época, um estudo encomendado pelos produtores de papel e celulose teve uma grande influência na política de financiamento do BNDE e, por conseguinte, no desenvolvimento do setor. O trabalho alertou o Banco para a necessidade de estabelecer critérios operacionais relativos ao dimensionamento das novas fábricas e ampliação das já existentes a serem apoiadas pelo BNDE. Apontava para a necessidade de se realizar novos investimentos direcionados à implantação de fábricas de celulose capazes de atingir escalas de produção capazes de gerar excedentes para exportação. O suprimento interno insatisfatório de celulose, aliado às dificuldades de produção de celulose de boa qualidade em locais distantes dos maciços florestais fez com que surgissem muitas unidades de pequeno e médio porte produzindo celulose de qualidade inferior (BNDES, 1991).

Em 1966, surgiu a primeira empresa de grande porte para a produção de celulose de mercado para exportação. Trata-se da Borregaard S.A., subsidiária de uma firma norueguesa, e que foi implantada com uma capacidade de $500 \mathrm{t} /$ dia de celulose de fibra curta.

Em 1967, por meio da Resolução 276, o Conselho de Administração do BNDE decide conceder prioridade aos projetos de implantação ou ampliação de capacidade para produção de celulose e papel.

Além disso, na segunda metade da década de 60 o setor de papel e celulose é grandemente influenciado por duas medidas de política governamental: o Decreto Lei 5.106/66 e a Decisão 196/68 do BNDE.

Em meados da década de 60, foi promulgado o Decreto-Lei 5.106/ 66 para viabilizar a implantação de maciços florestais pelas empresas e, assim, cumprir as determinações do Código Florestal, promulgado em 1965.

Este decreto-lei regulamentou os incentivos fiscais, previstos no Código Florestal de 1965, destinados a gerar recursos para investimentos em reflorestamentos. Assim, o referido decreto-lei permitiu às pessoas físicas abaterem da renda bruta as importâncias efetivamente aplicadas nesta atividade no ano-base da tributação e às pessoas jurídicas abater até 50\% do Imposto de Renda devido (Bacha, 1991). Os resultados da regulamentação dos incentivos fiscais foi uma grande expansão da área reflorestada nos anos seguintes.

A Decisão 196/68 do BNDE, por sua vez, estabeleceu que, a partir de então, os incentivos financeiros do Banco seriam direcionados para projetos que obedecessem a determinadas escalas mínimas de produção que, no caso da celulose, era de cerca de 100 t/dia. Adicionalmente, o Banco passou a exigir que as empresas demonstrassem a capaci- 
dade de suprir a si próprias com, no mínimo, 50\% das suas necessidades de madeira.

Segundo um documento do próprio Banco,

Ao propor que só apoiaria projetos de celulose com capacidade de mais de $100 \mathrm{t} / \mathrm{dia}$, o Banco estava adotando uma atitude pioneira: evitar desperdicios de matérias-primas e energia. Em outras palavras, redução de custos e maior eficiência no processo produtivo. [...] o licor negro (a lixívia), subproduto da fabricação de celulose, além de muito poluente, era matéria-prima recuperável sob a forma de energia e de produtos químicos. [...] Em projetos de menos de 100 t/dia, o subproduto, além de poluir, era desperdiçado, pois não justificava a instalação da caldeira de recuperação do licor' negro (BNDES, 1991, p. 11).

A importância desta medida pode ser compreendida quando se observa que o estudo encomendado pela ANFPC indicava que, em 1967, apenas seis fábricas de celulose no país tinham capacidade maior que $100 \mathrm{t} / \mathrm{dia}$.

Estas duas medidas foram responsáveis pela criação do que se transformaria no segmento exportador de celulose de mercado. Somente no ano de 1967 houve o surgimento de três importantes players: A Cia. Florestal Monte Dourado, que adquiriu as empresas proprietárias da área de Jari com a finalidade de implementar um projeto de reflorestamento e posterior fábrica de celulose; a Aracruz Florestal, que surgiu como uma empresa de prestação de serviços na área de reflorestamento; e a Florestas Rio Doce, controlada pela Cia. Vale do Rio Doce (Soto, 1992).

A partir de 1968, graças à prioridade dada pelo Banco aos projetos no setor de papel e celulose, todos os grupos líderes obtiveram financiamentos do BNDE.

Basta dizer que neste ano $10,7 \%$ das operações aprovadas pelo Banco destinaram-se ao setor. Este grande aumento é explicado pelo apoio ao projeto da empresa Borregaard, o qual teve uma grande importância para a evolução posterior de todo o setor. A dimensão do projeto ( $500 \mathrm{t} /$ dia) mostrava, em primeiro lugar, que o mercado mundial passava a apostar na evolução futura do mercado de fibra curta de eucalipto e, em segundo lugar, evidenciava a necessidade de apropriação das economias de escala como fonte principal da competitividade internacional (BNDES, 1991).

Como o projeto representaria cerca de $10 \%$ do valor total da pauta de exportações brasileira no ano de 1967, o BNDE decidiu apoiá-lo, 
inclusive participando acionariamente do projeto. Isto é, graças ao projeto Borregaard, o Banco iniciou uma política acionária direta em determinados projetos.

No início da década de 70, graças a pressões do BNDE, a Resolução 1 1/72 do Conselho de Desenvolvimento Industrial (CDI) fixou novas escalas mínimas para que os projetos industriais de produção de celulose recebessem incentivos oficiais. O CDI passou a considerar, para fins de concessão de incentivos, escalas mínimas de $500 \mathrm{t} /$ dia para a produção de celulose e com expansão prevista para $1.000 \mathrm{t} /$ dia.

A elevação, em cerca de dez vezes, da escala mínima exigida tinha como principal objetivo criar as condições para o surgimento de um segmento exportador de celulose de fibra curta.

Não obstante, frente às pressões do empresariado, o CDI acabou por permitir que as empresas pudessem alcançar a escala mínima exigida em duas etapas. A primeira, no entanto, deveria atingir um mínimo de $500 \mathrm{t} /$ dia.

A Resoluçāo 11/72 constituiu-se num indicativo das intenções do BNDE. Tratava-se de buscar uma maior eficiência e redução de custos por meio da apropriação das economias de escala, bem como explorar de forma mais intensa as vantagens comparativas brasileiras na produção de celulose de eucalipto (BNDES, 1991).

A crise do petróleo em 1973 só veio reforçar este posicionamento. Frente à brutal elevação dos preços das matérias-primas no mercado internacional, o país, grande importador desses produtos, passou a enfrentar enormes déficits em conta corrente.

A estratégia governamental baseou-se, então, em "completar" o processo de substituição de importações, privilegiando a produção de matérias-primas e bens de capital. Para tanto, o BNDE passou a dispor dos recursos do PIS-Pasep.

No início de 1974, o Conselho do BNDE aprovou o Plano de Ação para o período 1974 - 1978 o qual estabelecia que os projetos que tivessem como objetivo a exportação teriam estímulo prioritário.

Quanto ao setor de papel e celulose, o Plano estabelecia o seguinte (BNDES, 1991, p. 23):

... a meta específica do setor deve levar em conta não só o atendimento do consumo interno, como também a participação mais expressiva do País no mercado internacional.

Nesse sentido, pretende o BNDE dar apoio a projetos de grande porte que concorram para que a economia brasileira atinja um nível de produção de celulose superior a 2,5 milhões de toneladas em 1978, formando, ao mes- 
mo tempo, a massa crítica que garanta uma capacidade de produção superior a 3 milhões de toneladas em 1980.

Assim, em 1974, inserido na estratégia do II Plano Nacional de Desenvolvimento (PND), foi elaborado o I Programa Nacional de Papel e Celulose (I PNPC). O objetivo era alcançar a auto-suficiência tanto em papel quanto em celulose, prevendo, para esta última, a geração de excedentes exportáveis.

Elaborado num momento de euforia da economia brasileira e de alta no preço da celulose no mercado internacional, o plano previa a instalação de treze grandes plantas até 1980, baseando-se num modelo tripartite com igual participação do Estado, capital privado nacional e capital privado estrangeiro. Contudo, somente cinco projetos chegaram a ser instalados, e coube ao Estado a responsabilidade pela maior parte do investimento (Paladino, 1985).

Assim, novamente o governo, por meio do então BNDE, desempenhou um papel importante na execução de investimentos no setor de papel e celulose, proporcionando uma série de vantagens para as empresas do setor, tais como crédito subsidiado de longo prazo, participação direta no capital das empresas e auxilio à capitalização das empresas privadas nacionais por intermédio de programas especiais. Assim, as empresas líderes receberam financiamento direto subsidiado, participação acionária da FIBASE (posteriormente BNDESPAR) em até $50 \%$ do capital, crédito FINAME para aquisição de equipamentos fabricados no país e aval para importação de equipamentos, além de financiamento a acionistas (Soto, 1992).

Tal participação, no entanto, era feita por intermédio da aquisição de ações preferenciais unicamente, pois a filosofia da FIBASE era a de não interferir na administração dos negócios privados. Além do mais, o Banco venderia sua participação, preferencialmente aos acionistas controladores do empreendimento tão logo o projeto amadurecesse. Isto, contudo, não evitou que o Banco fosse levado a tornar-se o controlador e administrador de certas empresas que passaram por dificuldades técnicas de implementação ou insucesso gerencial (BNDES, 1991).

Na década de 70, começaram a operar três grandes empresas produtoras de celulose de mercado: a Borregaard entra em operação em 1972; a Celulose Nipo-Brasileira (CENIBRA) é fundada em 1973 e inicia as operações em 1977; a Aracruz Celulose inicia suas operações em 1978 com uma capacidade de produção que representava, naquela época, $25 \%$ 
da capacidade nacional de produção de celulose de fibra curta. Além disso, a Cia. Monte Dourado iniciou o processo para a importação do Japão de uma fábrica para a produção de celulose de fibra curta.

$\mathrm{Na}$ década de 80 , a indústria brasileira de celulose alcançou sua maturidade e se consolidou operando com equipamentos compativeis com a tecnologia mundial e integrados com a produção florestal. A indústria brasileira já era, nessa época, auto-suficiente na produção de matériaprima florestal plantada e, assim, adaptada a esse tipo de pressão ambiental.

A crise econômica geral que marcou este período não impediu que o BNDES continuasse a financiar investimentos no complexo florestal. $\mathrm{Na}$ segunda metade da década iniciou-se um novo ciclo de investimentos na modernização e ampliação de capacidade produtiva na indústria. O segundo Programa Nacional de Papel e Celulose (II PNPC) previa investimentos de cerca de US $\$ 9,6$ bilhões para o período de 1987 a 1995, dos quais dois terços destinavam-se para a ampliação da produção de celulose. Ao contrário do I PNPC, lançado em 1974, o segundo plano foi uma iniciativa dos produtores e não do governo. Além disso, incluiu tão-somente uma programação de investimentos produtivos sem contemplar um conjunto articulado de medidas como aconteceu na década de 70. $\mathrm{Na}$ verdade, o principal objetivo do II PNPC era obter linhas de financiamento de longo prazo do BNDES para viabilizar um novo ciclo de investimentos (Soto, 1992). O início da década de 90 marca uma fase de grandes desembolsos do BNDES ao setor (ver figura 1).

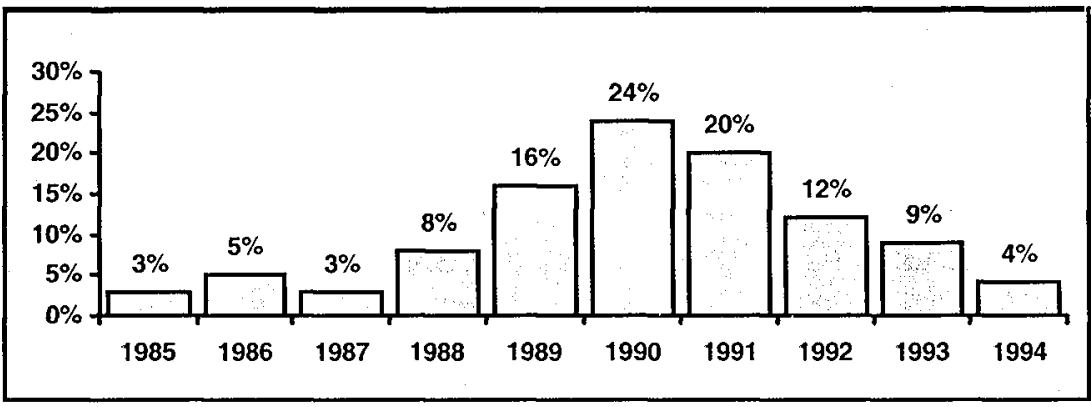

Fonte: Macedo et al. (1995).

Figura 1: Desembolsos do BNDES para o setor de celulose e papel em relação aos desembolsos totais do Banco (valores em \%). 1985 - 1994

Desta forma, o período de 1985 a 1995 marcou o segundo ciclo de investimentos no setor. Foi dentro do II PNPC que se viabilizou a dupli- 
cação da capacidade da Aracruz e o projeto Bahia Sul, em que o BNDES participa com capital de risco.

3 A participação do Brasil no comércio externo de celulose

Os resultados das políticas de incentivo à indústria brasileira exportadora de celulose podem ser avaliados por seu desempenho exportador. As exportações brasileiras deram um salto considerável a partir de 1978, e o viés exportador do segmento de celulose de mercado pode ser percebido pela evolução das exportações que passaram de 39.600 toneladas em 1970 para 2.526.100 toneladas em 1998 (Figura 2).

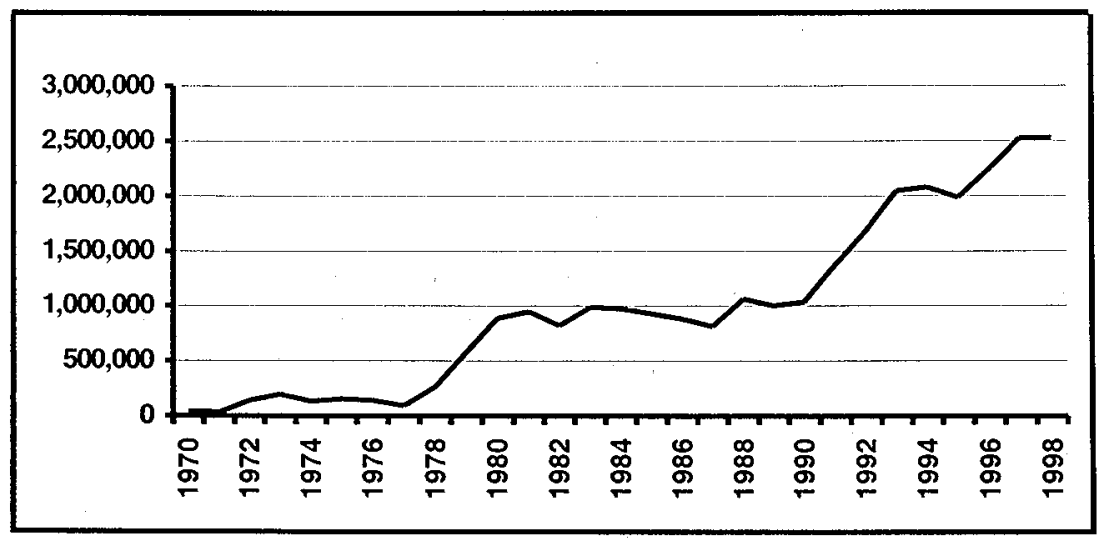

Fonte: http://www fao.org

\section{Figura 2: Evolução das exportações brasileiras de celulose no periodo de 1970 - 1998 (em toneladas)}

No panorama mundial, o Brasil tornou-se o maior produtor de celulose de fibra curta (hardwood pulp) do mundo e também o maior exportador (Tabela 1).

Considerando-se o total de celulose produzido (fibra longa e fibra curta), o país é o sétimo maior produtor de celulose no mundo. No entanto, a produção de celulose de fibra longa (softwood pulp) é, na sua maioria, feita por companhias integradas, destinando-se, basicamente, para o mercado interno. 
Tabela 1: Principais produtores e exportadores de celulose de eucalipto no mundo em 1997

\begin{tabular}{ccc}
\hline PAí́s & PRODUÇÃO (\%) & EXPORTAÇÃO $\%)$ \\
\hline Brasil & 50 & 45 \\
Portugal & 19 & 20 \\
Espanha & 15 & 17 \\
Chile & 5 & 5 \\
África do Sul & 5 & 4 \\
Outros & 6 & 9 \\
\hline
\end{tabular}

Fonte: Valença \& Mattos (1999a).

No mercado externo, a concorrência em nível das empresas é mostrada na Tabela 2 , refletindo a divisão de mercado mostrada na Tabela 1 .

Tabela 2: Maiores concorrentes das empresas brasileiras

\begin{tabular}{|c|c|c|c|c|}
\hline Empresa & Aracruz & Cenibra & $V C P$ & Riocell \\
\hline \multirow{5}{*}{$\begin{array}{l}\text { Maiores } \\
\text { concorrentes }\end{array}$} & Cenibra (Brasil) & Aracruz (Brasil) & Aracruz (Brasil) & Aracruz (Brasil) \\
\hline & Ence (Espanha) & Ence (Espanholal & Bahia Sul (Brasil) & Ence (Espanha) \\
\hline & $\begin{array}{l}\text { Portucel } \\
\text { (Portugal) }\end{array}$ & $\begin{array}{l}\text { Portucel } \\
\text { (Portugal) }\end{array}$ & Ence (Espanhal & Cenibra (Brasil) \\
\hline & Bahia Sul (Brasill) & Bahia Sul (Brasil) & Celbi (Espanha) & $\begin{array}{c}\text { Portucel } \\
\text { (Portugal) }\end{array}$ \\
\hline & VCP (Brasill) & VCP (Brasill) & Cenibra (Brasill) & Bahia Sul (Brasill) \\
\hline
\end{tabular}

Fonte: Dados da pesquisa.

Quanto aos compradores, os maiores importadores de celulose no mundo, considerando-se o percentual médio de suas importações no período de 1980 a 1998, são os EUA, a Alemanha, o Japão, a Itália, o Reino Unido, a França e a Coréia do Sul.

A tabela 3 demonstra o destino das exportações de celulose do Brasil. Como seria de se esperar, nossos maiores compradores são aqueles citados acima. No entanto, os Países Baixos (Bélgica e Luxemburgo), embora não sejam grandes importadores em termos mundiais, são um importante mercado para o Brasil. De fato, juntando-se a eles, EUA e Japão, observar-se-á que mais de $50 \%$ das exportaçōes brasileiras do produto no período 1989 - 1999 foram destinadas a estes países. 
Os outros mercados importantes, tais como Itália, França e Alemanha, absorveram algo em torno de $15 \%$ das exportações de celulose do Brasil.

Tabela 3: Destino das exportações brasileiras de celulose (em mil toneladas) e participação percentual de cada país no total exportado pelo Brasil no período 1989 - 1999

\begin{tabular}{|c|c|c|c|c|c|c|c|c|c|c|c|c|}
\hline \multirow[t]{2}{*}{ Ano } & \multicolumn{2}{|c|}{ EUA } & \multicolumn{2}{|c|}{$\begin{array}{l}\text { Bélgica e } \\
\text { Luxemburgo }\end{array}$} & \multicolumn{2}{|c|}{ Japão } & \multicolumn{2}{|c|}{ Reino Unido } & \multicolumn{2}{|c|}{$\begin{array}{c}\text { Coréía do } \\
\text { Sul }\end{array}$} & \multicolumn{2}{|c|}{ Outros países } \\
\hline & $\begin{array}{l}\text { Volv- } \\
\text { me }\end{array}$ & $\begin{array}{l}\% \text { no } \\
\text { total }\end{array}$ & $\begin{array}{l}\text { Volu- } \\
\text { me }\end{array}$ & $\begin{array}{l}\% \text { no } \\
\text { total }\end{array}$ & $\begin{array}{l}\text { Volu- } \\
\text { me }\end{array}$ & $\begin{array}{l}\% \text { no } \\
\text { total }\end{array}$ & $\begin{array}{l}\text { Volu- } \\
\text { me }\end{array}$ & $\begin{array}{l}\% \text { no } \\
\text { total }\end{array}$ & $\begin{array}{l}\text { Volu- } \\
\text { me }\end{array}$ & $\begin{array}{l}\% \text { no } \\
\text { total }\end{array}$ & $\begin{array}{l}\text { Volu- } \\
\text { me }\end{array}$ & $\begin{array}{l}\% \text { no } \\
\text { total }\end{array}$ \\
\hline 1989 & 280 & 27,94 & 264 & 26,32 & 212 & 21,16 & 45 & 4,44 & 17 & 1,73 & 182 & 18,15 \\
\hline 1990 & 331 & 31,88 & 276 & 26,54 & 207 & 19,95 & 51 & 4,92 & 33 & 3,17 & 149 & 14,34 \\
\hline 1991 & 440 & 31,84 & 344 & 24,85 & 249 & 17.99 & 76 & 5,48 & 72 & 5,20 & 225 & 16,25 \\
\hline 1992 & 476 & 28,35 & 436 & 26,00 & 241 & 14,35 & 104 & 6,20 & 107 & 6,39 & 360 & 21,43 \\
\hline 1993 & 575 & 23,88 & 530 & 21,98 & 353 & 14,66 & 124 & 5,13 & 149 & 6,18 & 726 & 30,10 \\
\hline 1994 & 564 & 27,19 & 460 & 22,20 & 343 & 16,54 & 119 & 5,74 & 114 & 5,50 & 480 & 23,13 \\
\hline 1995 & 592 & 29,82 & 458 & 23,11 & 328 & 16,55 & 126 & 6,36 & 96 & 4,86 & 412 & 20,75 \\
\hline 1996 & 582 & 25,98 & 459 & 20,51 & 362 & 16,18 & 166 & 7,41 & 204 & 9,11 & 496 & 22,12 \\
\hline 1997 & 605 & 24,17 & 367 & 14,66 & 470 & 18,75 & 212 & 8,45 & 134 & 5,33 & 795 & 31,72 \\
\hline 1998 & 682 & 24,30 & 441 & 15,71 & 422 & 15,03 & 228 & 8,13 & 136 & 4,86 & 942 & 33,56 \\
\hline 1999 & 810 & 26,04 & 442 & 14,22 & 427 & 13,72 & 226 & 7,25 & 161 & 5,18 & 1071 & 34,44 \\
\hline
\end{tabular}

Fonte: SECEX.

Do ponto de vista das empresas individuais, os maiores países compradores são indicados na tabela 4. 
Tabela 4: Maiores compradores da celulose brasileira por empresa

\begin{tabular}{c|cccc}
\hline Empresa & Aracruz & Cenibra* & VCP & Riocell \\
\hline \multirow{4}{*}{$\begin{array}{c}\text { Países } \\
\text { compradores }\end{array}$} & EUA & Japão & EUA & Coréia \\
& Alemanha & Europa & Alemanha & Itália \\
& Reino Unido & EUA & Áustria & França \\
& França & Ásia & Itália & Alemanha \\
& Áustria & América Latina & & Argentina \\
\hline
\end{tabular}

Fonte: Dados da pesquisa

Nota: A Cenibra não forneceu, individualmente, os países compradores para as regiões mostradas na tabela.

As tabelas 5 e 6 mostram as principais características dos principais compradores da celulose brasileira. A partir dos dados ali contidos, pode-se observar que os EUA, nosso maior comprador, é capaz de produzir praticamente toda a celulose que consome, no entanto, dado o tamanho de sua economia, tanto suas exportações de celulose quanto suas importações têm uma importância bastante significativa nos fluxos de comércio do produto. O mesmo acontece com papel e papelão, pois o país possui a maior capacidade de produção do planeta, a qual é capaz de suprir quase a totalidade de seu consumo aparente de papel e papelão.

Tabela 5: Principais características dos maiores importadores de celulose do Brasil

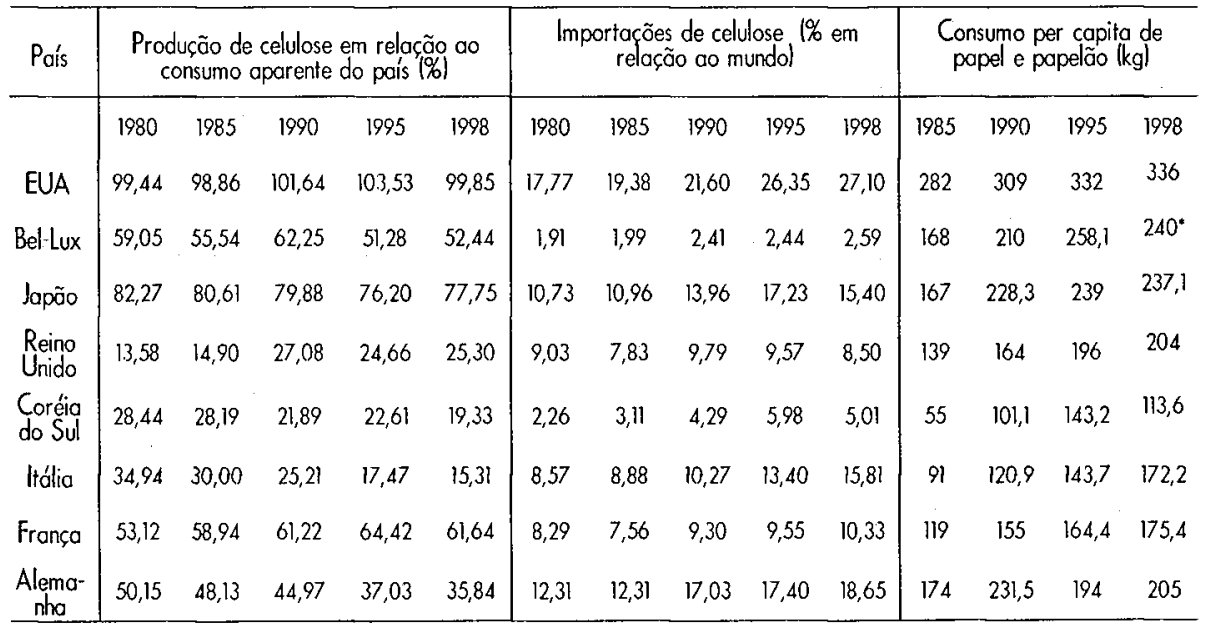

Fonte: PPI Annual Review, International Financial Statistics (FMI) e http/l:www fao.org Nota: * estimado. 
Tabela 6: Principais características da indústria de papel e papelão dos maiores importadores de celulose do Brasil

\begin{tabular}{|c|c|c|c|c|c|c|c|c|c|c|c|c|}
\hline \multirow[t]{2}{*}{ País } & \multicolumn{4}{|c|}{$\begin{array}{l}\text { Capacidade de produção de } \\
\text { papel e papelão (mil t/anol }\end{array}$} & \multicolumn{4}{|c|}{$\begin{array}{l}\text { Capacidade de producão de } \\
\text { papel e papelão (\% em } \\
\text { relação ao mundol }\end{array}$} & \multicolumn{4}{|c|}{$\begin{array}{l}\text { Produção de papel e papelão } \\
\text { em relação co consumo }\end{array}$} \\
\hline & 1985 & 1990 & 1995 & 1998 & 1985 & 1990 & 1995 & 1998 & 1985 & 1990 & 1995 & 1998 \\
\hline EUA & 68.457 & 76241 & 87.832 & 92900 & 31,95 & 35,58 & 40,99 & 43,36 & 89,42 & 91,95 & 95,13 & 94,56 \\
\hline Bel-Lux & 620 & 1250 & 1475 & 1272 & 0,29 & 0,58 & 0,69 & 0,59 & 54,45 & 58,23 & 53,63 & 58,39 \\
\hline Japão & 24.043 & 30728 & 31682 & 33.957 & 11,22 & 14,34 & 14,79 & 15,85 & 100,47 & 99,32 & 98,08 & 99,20 \\
\hline $\begin{array}{l}\text { Reino } \\
\text { Unido }\end{array}$ & 3.955 & 5360 & 6.350 & 6.960 & 1,85 & 2,50 & 2,96 & 3,25 & 47,88 & 51,76 & 55,12 & 54,96 \\
\hline $\begin{array}{l}\text { Coréia do } \\
\text { Sul }\end{array}$ & 2780 & 5020 & 7.285 & 10.549 & 1,30 & 1,89 & 2,62 & 3,02 & 104,91 & 104,49 & 104,51 & 147,85 \\
\hline Itália & 5200 & 6300 & 7.850 & 9.375 & 2,43 & 2,94 & 3,66 & 4,38 & 87,52 & 80,62 & 81,84 & 86,04 \\
\hline França & 5500 & 7400 & 10.435 & 10.140 & 2,57 & 3,45 & 4,87 & 4,73 & 81,77 & 80,79 & 89,58 & 86,15 \\
\hline Alemanha & 10242 & 13.042 & 16110 & 17251 & 4,78 & 6,09 & 7,52 & 8,05 & 87,11 & 82,50 & 93,64 & 96,77 \\
\hline
\end{tabular}

Fonte: PPI Annual Review e http/l:www.fao.org.

Quanto a Bélgica-Luxemburgo, a produção de celulose equivale à metade de seu consumo aparente. $\mathrm{Na}$ produção de papel e papelão, embora o país tenha dobrado sua capacidade de produção entre 1985 e 1998, o elevado consumo per capita destes itens, aliado a ainda pequena capacidade instalada, faz com que o país produza apenas algo em torno de $55 \%$ de seu consumo aparente de papel e papelão.

O Japão, por sua vez, produz pouco mais que $3 / 4$ de seu consumo aparente de celulose, mas, da mesma forma que os EUA, o tamanho relativo de sua economia faz com que ele se torne um grande importador. Não obstante, ao contrário deste último, o país não é um grande player no mercado internacional de papel e papelão.

No que diz respeito ao Reino Unido, há uma grande dependência da celulose importada uma vez que somente $1 / 4$ do consumo aparente é produzido internamente. O mesmo acontece com papel e papelão, cuja produção supre apenas pouco mais da metade do consumo aparente.

Outros países bastante dependentes da celulose importada são 
a Coréia do Sul, a Itália, a França e a Alemanha. Destes, apenas a França vem diminuindo suas necessidades. Os demais apresentam um volume de produção cada vez menor em relação a seu consumo. A Coréia do Sul, por exemplo, é um grande exportador de papel e papelão e praticamente quadruplicou sua capacidade instalada de produção entre 1985 e 1998. Aliado a isto, o forte crescimento da sua economia fez com que o consumo per capita destes insumos praticamente dobrassem no período.

A Alemanha continua grandemente dependente de importações de celulose e, dado o tamanho de sua economia, ela torna-se um dos maiores importadores do mundo. De modo semelhante aos EUA, o país apresenta uma grande capacidade de produção de papel e papelão (cerca de $8 \%$ da capacidade mundial) e também é um grande player neste mercado, sendo responsável por $8 \%$ do total exportado e, ao mesmo tempo, por algo em torno de $10 \%$ do total importado.

No âmbito mundial, destacam-se, como grandes produtores e, portanto, concorrentes do Brasil - , a América do Norte, a Comunidade Européia, a Escandinávia, a Península Ibérica, além de países como a África do Sul e Chile.

De acordo com BNDES (1993, p. 29),

... os líderes mundiais ainda são as economias desenvolvidas. A proximidade dos principais mercados consumidores (Europa, América do Norte e Japão) confere às empresas que operam nestes países vantagens competitivas estruturais, tais como: custos de comercialização e distribuição menores, integração com redes de distribuição e maior possibilidade de interação com o mercado final (o que permite a adoção de estratégias do tipo full satisfaction). Outras vantagens competitivas estão associadas a melhores condições de infra-estrutura física e científico-tecnológica, maior interação com fabricantes de equipamentos e possibilidades de se favorecer de políticas protecionistas que venham a ser adotadas.

A América do Norte é o maior mercado produtor e consumidor. Nos EUA, a indústria de papel e celulose é vinculada à indústria de construção civil e à indústria madeireira, de sorte que a produção de celulose é um subproduto da madeira serrada, cujos preços chegam a ser até cinco vezes maiores que os da madeira para celulose. Este país, no entanto, sofre pressões de custo crescentes. $\mathrm{Na}$ costa-oeste, sobressaem a inexistência de madeira, as pressões 
ambientais e a queda no rendimento das florestas mais novas. No Sul, há o problema do custo elevado das terras e da exaustão das florestas nativas. O Canadá, por sua vez, passou a enfrentar os problemas de escassez potencial de recursos florestais de alta qualidade e pressão dos ambientalistas para que as florestas públicas não sejam exploradas para fins industriais (BNDES, 1993).

Não obstante, EUA e Canadá, juntos, detinham, como pode-se depreender da Tabela 6 , mais de $46 \%$ do market share relativo às exportações mundiais. Estes dois países, aliados aos países escandinavos, controlam o mercado mundial por intermédio do cartel NORSCAN.

Os países escandinavos têm grandes vantagens competitivas, por conta de seu grande potencial financeiro, liderança tecnológica, maior valor agregado dos produtos e liderança de mercado, especialmente na distribuição. Além disso, a forte associação com os fabricantes de equipamentos proporcionou às empresas a possibilidade de tornarem-se líderes na produção de tecnologias mais amigáveis do ponto de vista ambiental (BNDES, 1993).

Porém, conforme BNDES (1993, p. 31),

"Nos anos setenta e com [sic] maior intensidade nos anos oitenta, a indústria escandinava passou a sofrer uma crescente competição no mercado europeu de paises como os EUA, Canadá, Brasil; Portugal e África do Sul. Todos estes produtores apresentavam custos de produçăo mais baixos e passaram a pressionar aquela indústria. A perda de competitividade da celulose produzida naqueles países levou a uma reação das empresas escandinavas. A principal estratégia foi a verticalização em direção à produção de papel, que se deu através da integração das plantas existentes e de processos vigorosos de reestruturação patrimonial, através da aquisição de empresas e pela fusão e/ou criação de joint ventures. Ao mesmo tempo, a indústria procurou estabelecer negócios nos países que emergiram no cenário internacional, tais como Brasil, Chile e Portugal."

Os demais players têm suas características principais delineadas na Tabela 7 . 
Tabela 7: Evolução das principais características dos países exportadores de celulose

\begin{tabular}{|c|c|c|c|c|c|c|c|c|c|c|c|c|}
\hline \multirow[t]{2}{*}{ País } & \multicolumn{4}{|c|}{ Copacidade de produção (mil t) } & \multicolumn{4}{|c|}{ Produção (mil } & \multicolumn{4}{|c|}{ Exportação (mil ton.) } \\
\hline & 1985 & 1990 & 1995 & 1998 & 1985 & 1990 & 1995 & 1998 & 1985 & 1990 & 1995 & 1998 \\
\hline EUA & 53165 & 59.425 & 62.087 & 64241 & 49.061 & 57217 & 60866 & 59132 & 3415 & 5.360 & 7.494 & 5.485 \\
\hline Canadá & 23903 & 26525 & 27551 & 28.291 & 20040 & 22839 & 25442 & 23.544 & 6851 & 7652 & 10.518 & 10641 \\
\hline Finlândia & 8990 & 9.850 & 11.46 & 13235 & 7837 & 8.765 & 10088 & 11.355 & 1415 & 1363 & 1302 & 1.635 \\
\hline Suécia & 9910 & 11.205 & 10.522 & 11.484 & 9123 & 10.215 & 10.506 & 10.860 & 3038 & 2768 & 2.560 & 2879 \\
\hline Brasil & 4.000 & 5.179 & 6.656 & 7447 & 3735 & 4.364 & 5909 & 6720 & 930 & 1.035 & 1958 & 2700 \\
\hline Indonésia & na & 1.108 & 2788 & 4.300 & 221 & 786 & 2.022 & 1.895 & na & 130 & 569 & 1.368 \\
\hline $\begin{array}{l}\text { Africa do } \\
\text { Sul }\end{array}$ & 1250 & 2256 & 2.250 & 2472 & 1270 & 1865 & 1868 & 2250 & 305 & 339 & 553 & 659 \\
\hline Chile & 900 & 1041 & 1800 & 2350 & 837 & 804 & 2113 & 2210 & 503 & 581 & 1625 & 1745 \\
\hline Norvego & 2115 & 2.510 & 2755 & 2.040 & 1851 & 2045 & 2485 & 2231 & 460 & 479 & 460 & 392 \\
\hline Espanha & 1540 & 1.750 & 1800 & 1850 & 1.394 & 1.592 & 1.602 & 1607 & $34 !$ & 514 & 643 & 673 \\
\hline Portugal & 1283 & 1.450 & 1681 & 1824 & 1328 & 1462 & 1630 & 1708 & 879 & 1066 & 971 & 1053 \\
\hline $\begin{array}{c}\text { Nova } \\
\text { Zelândia }\end{array}$ & 1493 & 1.471 & 1600 & 1600 & 1167 & 1234 & 1410 & 1.430 & 428 & 628 & 641 & 708 \\
\hline \multirow[t]{2}{*}{ País } & \multicolumn{4}{|c|}{$B / A \mid \%)$} & \multicolumn{8}{|c|}{ Market share nas exportações mundiais (\%) } \\
\hline & 1985 & 1990 & 1995 & 1998 & \multicolumn{2}{|c|}{1985} & \multicolumn{2}{|c|}{1990} & \multicolumn{2}{|c|}{1995} & \multicolumn{2}{|c|}{1998} \\
\hline EUA & 6,96 & 9,37 & 12,31 & 9,28 & \multicolumn{2}{|c|}{15,68} & \multicolumn{2}{|c|}{$2 \mathrm{I}, 49$} & \multicolumn{2}{|c|}{22,32} & \multicolumn{2}{|c|}{15,77} \\
\hline Canadá & 34,19 & 33,50 & 41,34 & 45,20 & \multicolumn{2}{|c|}{31,46} & \multicolumn{2}{|c|}{30,68} & \multicolumn{2}{|c|}{31,33} & \multicolumn{2}{|c|}{30,59} \\
\hline Finlândia & 18,06 & 15,56 & 12,91 & 14,40 & \multicolumn{2}{|c|}{6,50} & \multicolumn{2}{|c|}{5,47} & \multicolumn{2}{|c|}{3,88} & \multicolumn{2}{|c|}{4,70} \\
\hline Suécia & 33,30 & 27,09 & 24,37 & 26,51 & \multicolumn{2}{|c|}{13,95} & \multicolumn{2}{|c|}{11,10} & \multicolumn{2}{|c|}{7,63} & \multicolumn{2}{|c|}{8,28} \\
\hline Brasil & 24,89 & 23,72 & 33,13 & 40,17 & \multicolumn{2}{|c|}{4,27} & \multicolumn{2}{|c|}{4,15} & & 83 & & 76 \\
\hline Indonésia & na & 16,54 & 28,14 & 72,19 & & & & & & 69 & & 93 \\
\hline $\begin{array}{l}\text { Africa do } \\
\text { Sul }\end{array}$ & 24,05 & 18,17 & 29,61 & 29,29 & & & & & & 35 & & 90 \\
\hline Chile & 60,10 & 72,28 & 76,92 & 78,96 & & 31 & & & & 84 & & 02 \\
\hline Noruega & 24,85 & 23,43 & 18,49 & 17,57 & & וו & & & & 37 & & 13 \\
\hline Espanho & 24,48 & 32,28 & 40,14 & 41,90 & & & & & & 92 & & 94 \\
\hline Portugal & 66,16 & 72,93 & 59,54 & 61,65 & & 3 & & & & 89 & & 03 \\
\hline $\begin{array}{c}\text { Nova } \\
\text { Zelândia }\end{array}$ & 36,69 & 50,85 & 45,45 & 49,51 & & & & & & 91 & & 04 \\
\hline
\end{tabular}

Fonte: Os dados referentes à capacidade de produção foram retirados do PPI Annual Review (vários números). Os demais foram obtidos em wwu.fao.org. 


\section{Considerações finais}

No intuito de clarificar a maneira pela qual a indústria brasileira de celulose respondeu a estas novas exigências ambientais, tratou-se de investigar o processo histórico de evolução desta indústria e sua inserção no comércio internacional de celulose. Num primeiro momento, mostrou-se que o desenvolvimento desta indústria foi, em grande parte, condicionado pelas políticas públicas que objetivaram, desde sempre, torná-la competitiva no mercado mundial. Desta forma, a política pública, levada a cabo em boa parte pelo Banco Nacional de Desenvolvimento Econômico e Social (BNDES), contribuiu, de maneira decisiva, para a criação e organização do setor exportador de celulose brasileiro, tal qual ele se apresenta hoje.

Os resultados da política pública orientada para a criação de uma indústria capaz de gerar excedentes exportáveis foram avaliados em seguida, considerando-se a evolução das exportações brasileiras de celulose. Além disso, foram estabelecidas as principais características, tanto dos maiores concorrentes do Brasil como também dos maiores mercados consumidores de sua celulose. Evidenciou-se que os maiores concorrentes do país, no mercado de celulose de fibra curta, são os países da Península Ibérica e que os grandes mercados consumidores da celulose brasileira são os EUA, Bélgica-Luxemburgo e Japão, os quais respondem, historicamente, por mais de $50 \%$ de nossas exportações. Não obstante, há outros mercados importantes, como Itália, França e Alemanha, que absorvem juntos algo em torno de 15\% das exportações.

\section{Referências bibliográficas}

ANNUAL REVIEW. Pulp $\mathcal{B}$ Paper, vários números.

BACHA, C. J. C. "A expansão da silvicultura no Brasil". Rev. Bras. de Economia, v. 45, n 1, p. 145-168, jan./mar. 1991.

BNDES. A participação do sistema BNDES na evolução do setor de papel e celulose no Brasil. Rio de janeiro: DERIN/BNDES, 1991, 106p.

Estudo da competitividade da indústria brasileira. Campinas: IE/ UNICAMP, IEI/UFRJ, FDC, FUNCEX, 1993, 76p.

FAO. Faostat, http//:www.apps.fao.org (06 de novembro de 1999).

FAO. Forestry statistical yearbook (vários anos). 
IMF. International Financial Statistics (compact disc).

MENDONÇA JORGE, Maurício O. Emergência e consolidação do "padrão eucalipto" na indústria brasileira de celulose de mercado. Campinas, 1992, 166p. Dissertação (M.S.) - IE/UNICAMP.

PALADINO, G. G. Papel, técnica e capital: estudo sobre a evolução e mutação nos processos de trabalho e de produção do papel e análise do desenvolvimento do setor papeleiro no Brasil. Curitiba, 1985, 364 p. Dissertação (M.S.) - UFMG.

SCHERER, F. M. E ROSS, D. Industrial market structure and economic performance. 3.ed. Boston: Houghton Miffin, 1990, 713p.

SOTO, B. F. A. Da indústria do papel ao complexo florestal no Brasil: o caminho do corporativismo tradicional ao neocorporativismo. Campinas, 1992. Tese (Doutorado) - UNICAMP. 